\title{
Review Article \\ Receptor Tyrosine Kinases as Therapeutic Targets in Rhabdomyosarcoma
}

\author{
Lisa E. S. Crose ${ }^{1}$ and Corinne M. Linardic ${ }^{1,2}$ \\ ${ }^{1}$ Department of Pediatrics, Duke University Medical Center, Durham, NC 27710, USA \\ ${ }^{2}$ Department of Pharmacology and Cancer Biology, Duke University Medical Center, Durham, NC 27710, USA
}

Correspondence should be addressed to Corinne M. Linardic, linar001@mc.duke.edu

Received 15 September 2010; Accepted 1 November 2010

Academic Editor: Peter Houghton

Copyright (c) 2011 L. E. S. Crose and C. M. Linardic. This is an open access article distributed under the Creative Commons Attribution License, which permits unrestricted use, distribution, and reproduction in any medium, provided the original work is properly cited.

\begin{abstract}
Rhabdomyosarcomas (RMSs) are the most common soft tissue sarcomas of childhood and adolescence. To date, there are no effective treatments that target the genetic abnormalities in RMS, and current treatment options for high-risk groups are not adequate. Over the past two decades, research into the molecular mechanisms of RMS has identified key genes and signaling pathways involved in disease pathogenesis. In these studies, members of the receptor tyrosine kinase (RTK) family of cell surface receptors have been characterized as druggable targets for RMS. Through small molecule inhibitors, ligand-neutralizing agents, and monoclonal receptor-blocking antibodies, RTK activity can be manipulated to block oncogenic properties associated with RMS. Herein, we review the members of the RTK family that are implicated in RMS tumorigenesis and discuss both the problems and promise of targeting RTKs in RMS.
\end{abstract}

\section{Introduction}

The most common soft tissue sarcomas of childhood and adolescence are rhabdomyosarcomas (RMSs). These malignancies express skeletal muscle markers but are believed to be the result of dysregulated skeletal muscle differentiation of mesenchymal precursors. Like other sarcomas, RMS tumors are molecularly diverse; histological classification separates RMS into two major types, embryonal (eRMS) and alveolar rhabdomyosarcoma (aRMS). As the name implies, eRMS tumors consist of cells morphologically similar to embryonic muscle precursors. The histology of aRMS tumors is distinctive, with clusters of primitive, round cells and open spaces between cell sheets developing upon fixation in formalin, vaguely resembling lung alveoli [1]. The eRMS and aRMS subtypes differ not only in histological appearance but also in prognosis. Patients with eRMS have a generally favorable prognosis, while patients with aRMS do significantly worse, with a five-year survival rate of less than 50\% [2]. Furthermore, aRMS can be specified by the presence of a chromosomal translocation resulting in a PAX3-FOXO1 (or the less frequent PAX7-FOXO1, PAX3-NCOA1, or PAX3NCOA2 [3]) gene product. When metastatic, PAX3-FOXO1positive aRMS patients survive in fewer than $10 \%$ of cases [4]. Although staging of RMS still utilizes histology, recent gene profiling studies have suggested that a more accurate classification of RMS might be as fusion gene positive or negative $[5,6]$. Thus, modified classification of RMS may lead to better risk stratification at diagnosis and direct appropriate therapy.

Treatment for RMS has depended on a multimodal approach of surgery, chemotherapy, and radiation. This team strategy has resulted in an overall survival of RMS at about 70\% [7]. But as described above, high-risk patients have a poor prognosis, and treatment options are limited. It is believed that without targeted therapies specific for genetic abnormalities associated with RMS, the survival rate will not improve.

Over the past two decades, research into the molecular mechanisms of RMS has identified key genes and signaling pathways involved in disease pathogenesis. Opportunely, many groups have identified favorable molecular targets for 


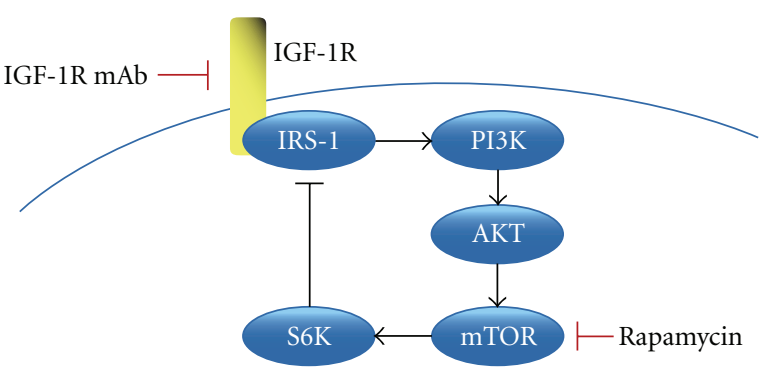

FIgURE 1: Rationale for dual treatment targeting the IGF-1R signaling pathway in RMS. Rapamycin inhibits mTOR signaling, preventing inhibitory feedback on IRS-1 which allows proliferative signals from IGF-1R to IRS-1, PI3K, and AKT. Dual treatment using rapamycin in combination with IGF-1R inhibition, such as monoclonal blocking antibodies, prevents signaling to these critical progrowth signaling nodes.

inhibition, such as cell surface receptors. In this review, we will describe the receptor tyrosine kinases (RTKs) associated with RMS and subsequently discuss the therapeutic potential of these targets.

\section{Receptor Tyrosine Kinases Associated with Rhabdomyosarcoma}

2.1. IGF-1R. The IGF-1R is a $150-\mathrm{kDa}$ transmembrane RTK expressed on almost all mammalian cells. It is a classical RTK, signaling through ligand occupancy, dimerization, and transmembrane signaling to the cytoplasm through the IRS-1 and IRS-2 adaptor proteins. Present during both embryogenesis and postnatally, IGF-1R is critical for the growth of a variety of mammalian tissue types [8]. In myogenesis, IGF-1R is essential for myoblast proliferation, and IGF ligands induce a strong proliferative response in myogenic precursors. IGF-1R signaling is also necessary for myogenic differentiation through upregulation of the myogenic cascade [9]. There are two known IGF-1R ligands, IGF-1 and IGF-2. While both of these ligands have a ubiquitous tissue distribution, IGF-1 is considered to exert its effects postnatally, while IGF-2 is thought to be dominant during embryogenesis [10]. Through numerous in vitro and in vivo studies performed by many groups, it is well established that IGF activation of IGF-1R is critical for both proliferation and differentiation of muscle cells.

The original evidence for upregulation of IGF-1R signaling in RMS came from early studies of IGF ligands in pediatric tumors. As such, IGF-2 was found to be upregulated in both primary RMS tumor samples and cell lines $[11,12]$, mechanistically the result of loss of imprinting of the maternal or duplication of the active IGF2 allele $[13,14]$. IGF-1R was later found to be upregulated in aRMS by the PAX3-FOXO1 fusion gene [15]. In this way, increased expression of both IGF-2 and IGF-1R leads to a strong mitogenic feed-forward signaling loop within the tumor.

The role of the IGF-1R signaling pathway in RMS has been examined through experimental loss of function using multiple approaches. Antisense constructs, small molecule inhibitors, and receptor blocking antibodies to IGF-1R have all shown antiproliferative effects in preclinical studies of RMS cell lines and xenografts [12,16-25]. The mechanism of action appears to be through inhibition of cell proliferation by arrest in the G1 stage of the cell cycle due to downregulation of CDK1 $[19,21]$. Interestingly, cell lines that were the most sensitive to IGF-1R blockade were those with the highest levels of IGF-1R expression [16].

An understanding of the signaling pathways downstream of IGF-1R has been enhanced through studies using the small molecule inhibitor, rapamycin. Rapamycin inhibits mTOR, a PIKK family member kinase that responds to changes in nutrient availability and cellular stresses. RMS sensitivity to rapamycin is mediated by IGF-1R signaling, demonstrating that the mTOR pathway is downstream of IGF-1R $[17,26]$. As shown in Figure 1, in the IGF-1R signaling pathway, IGF$1 \mathrm{R}$ signals to IRS-1 and AKT, which then signals to mTOR. Paradoxically, treatment of cancer cells with rapamycin activates AKT, due to blockade of a feedback loop via ribosomal S6 kinase (S6K) that normally inhibits IRS-1 [27]. This effect can be reversed by inhibiting IGF-1R. Through dual treatment of RMS tumors with rapamycin and IGF$1 \mathrm{R}$ inhibitors, the proliferative IGF-1R signaling cascade can be dramatically reduced. In this way, IGF-1R blockade has become an attractive proposed treatment for RMS and other IGF-driven cancers [16, 28, 29].

IGF-1R inhibitors are one of many classes of compounds tested in the Pediatric Preclinical Testing Program (PPTP). This NCI-funded program provides a preclinical screening platform to test new agents that may have activity against pediatric cancers. As shown in Table 1, the IGF-1R inhibitor IMC-A12 showed effectiveness in RMS xenografts, while SCH 717454 had a partial effect. These studies, in addition to the preclinical data described above, provide a strong rationale to pursue IGF-1R inhibitors in clinical trials for pediatric RMS patients.

As shown in Table 2, phase I and phase II trials of RTK small molecule inhibitors, monoclonal antibodies against RTK ligands, and monoclonal antibodies against RTKs have been under investigation since the year 2000. Notably, inhibition of IGF-1R with monoclonal antibodies has been the most recent focus of these trials and, if successful, will be the first FDA-approved RTK-targeted therapy for RMS.

2.2. MET. MET is a proto-oncogene RTK necessary for cell proliferation, motility, and epithelial-mesenchymal transition. Similar to IGF-1R, MET is also $150 \mathrm{kDa}$ and shows broad tissue expression in embryonic and postnatal tissues. In contrast to IGF1-1R, MET has only one ligand, termed hepatocyte growth factor (HGF). In the context of myogenesis, limb mesenchyme secretes HGF, which directs myogenic precursors to the limb bud. In this way, MET signaling regulates delamination and migration of muscle precursors from the embryonic dermomyotome [30]. MET also promotes cell proliferation in muscle precursors when activated with HGF in vitro [31]. When these cells stop proliferating and induce differentiation, HGF and MET expression decreases [32]. Thus, MET promotes both myoblast proliferation and migration processes in normal cells. 
Table 1: Results of RTK inhibitors used in Pediatric Preclinical Testing Program.

\begin{tabular}{|c|c|c|c|c|c|}
\hline Intended target & Inhibitor & $\begin{array}{l}\text { Additional } \\
\text { targets }\end{array}$ & $\begin{array}{l}\text { In vivo response, } \\
\text { RMS xenografts* }\end{array}$ & Conclusions & Ref. \\
\hline EGFR, ErbB2 & Lapatinib & Erk1/2, Akt & $1 / 5$ & Limited effectiveness in all xenografts tested & {$[30]$} \\
\hline IGF-1R & IMC-A12 & N/A & $6 / 6$ & $\begin{array}{l}\text { Tumor growth inhibition in most solid tumor } \\
\text { xenografts, most effective in RMS xenografts }\end{array}$ & [25] \\
\hline IGF-1R & SCH 717454 & N/A & $2 / 4$ & $\begin{array}{l}\text { Tumor growth inhibition in many solid tumor } \\
\text { xenografts }\end{array}$ & [31] \\
\hline PDGFR & Sunitinib & $\begin{array}{c}\text { c-KIT, } \\
\text { VEGFR2, } \\
\text { FLT3 }\end{array}$ & $5 / 6$ & $\begin{array}{l}\text { Tumor growth delay, inhibition in most solid } \\
\text { tumor xenografts }\end{array}$ & {$[32]$} \\
\hline Raf1 & Sorafenib & $\begin{array}{c}\text { VEGFR, } \\
\text { PDGFR, RET, } \\
\text { FLT3, c-KIT }\end{array}$ & $2 / 6$ & $\begin{array}{l}\text { Tumor growth inhibition in various tumor } \\
\text { xenografts }\end{array}$ & [33] \\
\hline SRC & Dasatinib & $\begin{array}{c}\text { ABL, c-KIT, } \\
\text { EPHA2, } \\
\text { PDGFR }\end{array}$ & $1 / 6$ & Limited effectiveness in solid tumor xenografts & {$[34]$} \\
\hline VEGFR1-3 & AZD2171 & $\begin{array}{l}\text { PDGFR, } \\
\text { c-KIT }\end{array}$ & $5 / 5$ & $\begin{array}{l}\text { Tumor growth inhibition in most solid tumor } \\
\text { xenografts }\end{array}$ & {$[35]$} \\
\hline
\end{tabular}

*Xenografts with "intermediate" or "high" response activity as defined by Maris et al. [50].

HGF is also known as "scatter factor," referring to its ability to induce cell motility. Accordingly, MET has been implicated in cytoskeletal reorganization and migration in cancer cells. In RMS cells, HGF promotes chemotaxis and invasion [33-35]. Because of these migratory effects of HGF/MET signaling, the role of this signaling pathway in tumor cell metastasis has been examined. Cells derived from bone marrow secrete HGF, and RMS cells have been shown to home to bone marrow, due in part to MET expression $[33,35,36]$. Furthermore, bone marrow aspirates from RMS patients with metastatic disease have elevated MET expression [37]. Therefore, a major role for MET is to confer migratory and metastatic properties.

MET-null and Splotch (PAX3 mutant) mice both exhibit loss of muscle precursor colonization in the limb bud $[30,38]$, which revealed an association of PAX3 with MET expression [39]. MET is a transcriptional target of PAX3 and PAX3-FOXO1, and RMS cell lines and tumors express elevated levels of MET compared to normal muscle [34, 40, 41]. Targeted knockdown of MET in human RMS cell lines decreases RMS cell proliferation in vitro and tumor burden in mouse xenograft models $[35,42]$. Therefore, in addition to regulating migration and metastasis, MET also appears to regulate proliferative properties in RMS.

Several genetically engineered mouse models of RMS either exploit MET signaling or demonstrate deregulated MET expression. The most robust murine model of RMS was generated through manipulation of the HGF/MET signaling axis. While transgenic $H G F$ mice were predisposed to a low incidence of many types of cancers, including skeletal muscle-derived tumors [43], transgenic HGF mice with a targeted deletion of the INK4A/ARF locus had a near complete penetrance of eRMS in young animals [44]. Mouse models utilizing the PAX3-FOXO1 fusion gene have also defined roles for MET. Conditional replacement of PAX3 with $P A X 3-F O X O 1$ results in abnormal delamination of myogenic progenitors from the somite that can be reversed with expression of a kinase-inactive MET [45]. aRMS has been modeled by conditional PAX3-FOXO1 at the PAX3 locus in either an INK4A/ARF or $p 53$-null background. MET upregulation was observed in all tumors derived, regardless of the genetic background [46].

Although there is clear evidence for the involvement of MET in RMS initiation, progression, and metastasis, to date there have been no clinical trials evaluating MET inhibition in the context of RMS. Since MET is implicated in many adult malignancies, and phase I clinical trials for monoclonal antibodies and small molecule inhibitors with anti-MET activity have recently begun, we should expect to see trials recruiting pediatric RMS patients.

2.3. EGFR, ErbB2. The ErbB family of RTKs is comprised of four members: EGFR (ErbB1, HER1), ErbB2 (HER2), ErbB3 (HER3), and ErbB4 (HER4). Members of this family are similar in size, at $190 \mathrm{kDa}$, and each are necessary for embryonic development. Each has been implicated in cancer initiation and progression but in different tissue types. Notably, ErbB3 is a noncatalytic receptor but exerts an oncogenic function through heterodimerization with other ErbB family members [47]. ErbB receptors regulate multiple levels of cell physiology in different tissues, including cytoskeletal rearrangement, proliferation, and evasion of apoptosis. In mouse myoblasts, EGFR is expressed and is active in both undifferentiated and differentiated cells. EGFR blockade in murine myotubes induced cell death, suggesting that EGFR regulates prosurvival signaling in myogenic cells [48]. EGFR has been associated with many adult malignancies, including breast, non-small cell lung cancer, glioblastoma, head and neck, gastric, genitourinary, and colorectal carcinomas [49]. Prognosis in these cancers can often be estimated by the presence or absence of EGFR mutations, deletions, or overexpression. 
TABLE 2: Clinical trials evaluating drugs that target RTKs or their ligands, with strata that include rhabdomyosarcoma.

\begin{tabular}{|c|c|c|c|c|c|c|c|}
\hline RMS tumor eligibility & $\begin{array}{c}\text { Patient } \\
\text { age } \\
\text { (years) }\end{array}$ & Drug & $\begin{array}{c}\text { Intended } \\
\text { RMS } \\
\text { Target }\end{array}$ & Additional Targets & Phase & Start date & Sponsor/ collaborator \\
\hline \multicolumn{8}{|c|}{ Small molecule inhibitors } \\
\hline Relapsed/refractory & $\geq 15$ & Imatinib & PDGFR & ABL, c-Kit & $\mathrm{I} / \mathrm{II}$ & Aug 2000 & EORTC \\
\hline Resistant & $\begin{array}{c}\geq 15 \text { but } \\
\leq 70\end{array}$ & Imatinib & PDGFR & $\mathrm{ABL}, \mathrm{c}-\mathrm{Kit}$ & II & Feb 2001 & Novartis \\
\hline Advanced & $\geq 10$ & Imatinib & PDGFR & ABL, c-Kit & II & Jun 2002 & $\mathrm{NCI}$ \\
\hline Refractory & $\leq 21$ & Erlotinib & EGFR & & $\mathrm{I}$ & Feb 2004 & COG/NCI \\
\hline Refractory & $\leq 21$ & Gefitinib & EGFR & & I & Sep 2005 & St. Jude's/Astra Zeneca \\
\hline $\begin{array}{l}\text { Metastatic/advanced/ } \\
\text { recurrent }\end{array}$ & $\geq 18$ & Sunitinib & PDGFR & $\begin{array}{l}\text { c-KIT, VEGFR2, } \\
\text { FLT3 }\end{array}$ & II & Apr 2007 & MSKCC/NCI \\
\hline Advanced & $\geq 13$ & Dasatinib & SRC & $\begin{array}{c}\text { ABL, c-KIT, } \\
\text { EPHA2, PDGFR }\end{array}$ & II & May 2007 & $\begin{array}{c}\text { SARC/ } \\
\text { Bristol-Myers Squibb }\end{array}$ \\
\hline Metastatic/recurrent & $\begin{array}{l}\geq 1 \text { but } \\
\leq 25\end{array}$ & Dasatinib & SRC & $\begin{array}{c}\text { ABL, c-KIT, } \\
\text { EPHA2, PDGFR }\end{array}$ & $\mathrm{I} / \mathrm{II}$ & Sep 2008 & $\begin{array}{c}\text { Beckman Research Institute/ } \\
\text { NCI }\end{array}$ \\
\hline $\begin{array}{l}\text { Metastatic/relapsed/ } \\
\text { refractory }\end{array}$ & $\geq 18$ & Pazopanib & VEGFR1-3 & PDGFR, c-KIT & III & Oct 2008 & EORTC \\
\hline Refractory/recurrent & $\begin{array}{l}\geq 2 \text { but } \\
\leq 18\end{array}$ & Cediranib & VEGFR1-3 & & I & Dec 2008 & $\mathrm{NCI}$ \\
\hline \multicolumn{8}{|c|}{ Monoclonal antibodies against RTK ligands } \\
\hline Metastatic & $\begin{array}{c}\geq 0.5 \text { but } \\
\leq 18\end{array}$ & Bevacizumab & VEGF & N/A & II & Jul 2008 & Hoffman-La Roche \\
\hline \multicolumn{8}{|c|}{ Monoclonal antibodies against RTKs } \\
\hline Recurrent/refractory & $\geq 2$ & $\mathrm{R} 1507$ & IGF-1R & N/A & II & Nov2007 & Hoffmann-La Roche/SARC \\
\hline $\begin{array}{l}\text { Unresectable/locally } \\
\text { advanced/ metastatic }\end{array}$ & $\geq 16$ & IMC-A12 & IGF-1R & N/A & $\mathrm{I} / \mathrm{II}$ & Jun 2008 & U. Chicago/NCI \\
\hline Metastatic/advanced & $\geq 12$ & IMC-A12 & IGF-1R & N/A & II & Jun 2008 & ImClone LLC \\
\hline Relapsed/refractory & $\leq 30$ & Cixutumumab & IGF-1R & N/A & II & Jan 2009 & COG/NCI \\
\hline Metastatic & $\leq 49$ & Cixutumumab & IGF-1R & N/A & Pilot & Jan 2010 & COG/NCI \\
\hline
\end{tabular}

Obtained from clinicaltrials.gov website September 2010.

ErbB family proteins were found to be expressed in RMS cells during screening for growth factor signaling pathway members [51-53]. While EGFR is more highly expressed in eRMS tumor tissue [54-56] ErbB2 expression is more prevalent in aRMS tumor tissue, and found in the majority of RMS tumors in the head and neck [55, 57]. ErbB3 is also expressed in RMS cells and may play a role in regulating differentiation, but ErbB4 has not been found to be expressed in RMS cells [52]. Notably, to date no mutations have been identified in the ErbB genes in RMS. Blocking EGFR expression by antisense methods decreases RMS cell proliferation in vitro [58]. Unfortunately, followup preclinical testing of EGFR inhibitors in vivo has not shown efficacy. As an example, the small molecule inhibitor lapatinib was tested in a PPTP screen but had little effect in solid tumors, suggesting that EGFR inhibition alone is not sufficient to inhibit tumorigenesis.

Expression of an activating ErbB2 mutation in combination with loss of p53 is sufficient to induce rhabdomyosarcoma in mouse models. The resulting tumors appear histologically similar to eRMS and express IGF-2 and IGF-1R [59]. This model was used to test a cancer vaccine developed against the ErbB2 receptor, which was successful in preventing spontaneous RMS formation in 50\% of mice examined [60]. Even though preclinical studies have not shown promise as monotherapy, ErbB2 may play a supportive role in RMS initiation.

Although inhibition of a single RTK may be beneficial in some circumstances, studies have suggested that this approach will likely not be sufficient treatment for RMS, and this appears to be true of EGFR. This has been appreciated in preclinical models, and therefore human clinical trial design has been modified to evaluate RTK inhibition in combination with a cytotoxic agent. Gefitinib, a small molecule inhibitor for EGFR, is being tested in phase I clinical trials in pediatric solid tumors, in combination with irinotecan [61]. Phase I clinical trials have been completed for erlotinib, which also targets EGFR, done in combination with temozolomide with few adverse effects [62].

2.4. PDGFR. The PDGFR family of RTKs includes PDGFR $\alpha$ and PDGFR $\beta$, both $200 \mathrm{kDa}$ in size, which homo- or heterodimerize to perform their signaling functions. While PDGFR $\alpha$ is believed to be critical in the development of 
neural, epithelial, and skeletal tissues, PDGFR $\beta$ is important for blood vessel formation and hematopoiesis [63]. In normal myogenesis, PDGFR activation is downregulated, implying that loss of PDGFR signaling is involved in the cell cycle exit that accompanies differentiation [64]. There are four ligands for PDGFR, PDGF-A through PDGFD. In myoblasts, PDGF-B promotes cell migration and proliferation and reduces differentiation in vitro $[65,66]$. Therefore, PDGFR signaling is important for embryogenesis, and specifically myogenesis by regulating proliferation, migration, and differentiation in myogenic precursors.

In RMS, the two PDGF receptors show increased expression [67-69], and PAX3-FOXO1 has been shown to activate transcription of PDGFR $\alpha$ [70]. Imatinib, a small molecule inhibitor of PDGFRs, has shown promise as an RMS therapy in preclinical models. In a mouse genetic model of RMS, high expression of PDGFR $\alpha$ was observed in advanced tumors. Loss of function of PDGFR $\alpha$ through siRNA or imatinib induced tumor cell apoptosis. When imatinib or PDGFR $\alpha$ blocking antibodies were used to treat RMS tumors in these mice, $50 \%$ of mice had at least a partial reduction of tumor growth [71]. PDGFR inhibition with sunitinib or sorafenib showed promise in PPTP screening, promoting tumor growth delay or inhibition, respectively (Table 1). However, both sunitinib and sorafenib are known to inhibit numerous other kinases, so these effects may not be due to PDGFR inhibition alone. Although targeting PDGFR alone has shown some promise in preclinical models, combination treatment with other chemotherapies may be more beneficial. In a mouse xenograft model of RMS, significant reduction of tumor burden was observed when imatinib was used in combination with the topoisomerase inhibitor topotecan [68].

In RMS patients, high expression of PDGFRs is associated with decreases in failure-free and overall survival, implicating PDGFR signaling in advanced stages of the disease $[53,72]$. The PDGFR inhibitor imatinib was tested in advanced sarcomas of various types in a phase II trial. Overall, the results did not support the use of imatinib as a monotherapy, as only $2 \%$ of participants saw an effect resulting in partial or complete remission [73]. However, combination treatment of imatinib with other targeted or cytotoxic agents may be more beneficial, as was seen in preclinical models [68].

2.5. VEGFR. The VEGFR family of RTKs is comprised of three members: VEGFR1 (FLT1), VEGFR2 (FLK1/KDR), and VEGFR3 (FLT4). VEGFRs on endothelial cells regulate multiple levels of angiogenesis by promoting endothelial cell proliferation, migration, sprouting, and survival. These receptors are activated by the five members of the VEGF ligand family, VEGF-A through VEGF-D, and placental growth factor (PIGF). VEGFs are produced in a wide variety of tissues in response to hypoxia, in order to recruit vasculature to the hypoxic area [74]. Interestingly, VEGFRs are also expressed in myoblasts, and VEGF promotes myoblast migration and survival. VEGFR expression is downregulated upon myogenic differentiation, suggesting that prolonged VEGFR signaling negatively regulates differentiation [75].
Similar to other cancer cells, when exposed to hypoxia, RMS cells increase their secretion of VEGF [28]. RMS cells express multiple isoforms of VEGF and VEGFRs, implying that RMS tumors may utilize an autocrine loop to not only promote tumor vascularity but induce tumor growth as well. This is supported by evidence that treatment of RMS cells in culture promotes proliferation, while treatment with VEGFR antibody blocked this effect [76]. Furthermore, inhibition of signaling downstream of VEGFR prevents expression of VEGF by RMS cells, suggesting a feed-forward loop promoting proliferation [77].

VEGFR inhibitors have shown promising results in preclinical studies. Monoclonal antibodies to VEGF and VEGFRs and small molecule inhibitors to VEGFRs have been tested in mouse xenografts of RMS reduced tumor volume and vascularity [50,78-81]. Notably, cisplatin-resistant RMS cells have increased expression of VEGF and VEGFRs, implicating this autocrine signaling in RMS cell survival. Cisplatin-resistant cells were sensitive to VEGFR inhibition, which also blocked VEGF expression [82]. In this way, highly aggressive tumor cells could be targeted with antiVEGFR therapy. In PPTP screening, VEGFR inhibitors have also shown potential. The inhibitors AZD2171, sorafenib, and sunitinib have each inhibited tumor growth in RMS xenograft models. Currently, there are multiple clinical trials testing VEGFR inhibition in RMS patients. These include the small molecule inhibitors sunitinib, pazopanib, and cediranib as well as the VEGF monoclonal antibody bevacizumab. These studies are ongoing, but whether the strong preclinical data for VEGFR inhibition will translate to positive outcomes in clinical trials remains to be seen.

2.6. FGFR. The FGF receptor (FGFR) family consists of four members, FGFR1 through 4, and vary in size (120-160 kDa), tissue distribution, and ligand affinity. FGFRs affect many aspects of cell and organism physiology including proliferation, migration, and differentiation through activation by FGF ligands, of which there are at least 23 [83]. FGFR4 is considered to be the predominant FGFR in skeletal muscle, regulating skeletal muscle differentiation in chick models and muscle regeneration in mice $[84,85]$. As is true for most of the RTKs reviewed here, FGFR4 expression in myoblasts decreases during differentiation, implying that FGFR4 is important in myogenic precursors [86].

While FGFR1 and FGFR3 have been observed to have increased expression in isolated RMS cases $[87,88]$, and FGF ligands are expressed in RMS cells and tissues [51, 89], signaling through FGFR4 has been the best characterized in RMS tumorigenesis. FGFR4 expression is upregulated in RMS cell lines and tumors [90, 91], and PAX3-FOXO1 promotes FGFR4 expression through $3^{\prime}$ enhancer regions [15]. Recently, FGFR4 was characterized as a regulator of RMS tumor growth and metastasis. Activating mutations within the kinase domain of FGFR4 were identified in 7\% (7 of 94) of RMS cases, demonstrating overactive FGFR4 signaling in RMS. These activating mutations were sufficient to transform cells, increase RMS lung metastasis, and decrease survival in mouse xenograft models. Blocking FGFR4 expression decreased RMS tumor size, cell migration, 
and metastasis, therefore characterizing FGFR4 as a possible molecular target for RMS [92]. FGFR4 is the most recent RTK implicated in RMS, and as such more research will be needed to verify that FGFR4 is a rational therapeutic target to pursue in preclinical and clinical settings.

\section{Regulation of RTK Expression in Rhabdomyosarcoma}

Since a signature mutation of aRMS is a chromosomal translocation resulting in the PAX3/7-FOXO1 or PAX3NCOA1/2 transcription factors, much attention has been focused on the genes regulated by these fusion proteins. In fact, IGF-1R, MET, PDGFR, VEGFR1, and FGFR4 have all been shown to be regulated by PAX3-FOXO1 either by activation of the RTK gene promoter or through $5^{\prime}$ or $3^{\prime}$ enhancing elements $[15,39,70,93]$. Since transcription factors are generally difficult to target due to chemical intractability, druggable PAX3-FOXO1 transcriptional targets such as RTKs could be more promising than inhibiting PAX3-FOXO1 itself.

Another regulator of RTKs in RMS is the tumor suppressor p53. The importance of p53 function in RMS has been underscored by its role in promoting RMS in mouse models when it is absent $[46,59]$. Mutations in p53 have been documented in both histological subtypes of RMS [94], and IGF-1R and PDGFR have been definitively shown to be upregulated in p53 loss-of-function experiments and downregulated when nonmutated $\mathrm{p} 53$ is added back to these systems [71, 95]. Although PAX3-FOXO1 and p53 regulation of RTK transcription in specific cases has been informative, there is a need for a better understanding of when and how RTK transcription is activated in RMS tumorigenesis.

Most recently, posttranscriptional regulation of genes has been shown to play a role in RMS tumorigenesis. The most focus has been on microRNAs mir-1 and mir-206, socalled "myo-mirs." Upon myogenic pathway induction, mir1 and mir-206 expression is upregulated, leading to posttranscriptional downregulation of mir-1 and mir-206 targets. Mir-1 and mir-206 have been found to be sufficient to induce myogenic differentiation in myoblasts [96]. RMS cell lines and tumors do not express mir-1 and mir-206 and therefore are not able to posttranscriptionally regulate mir- 1 and mir206 targets. Surprisingly, MET was found to be implicated in the mir-206 pathway. MET contains two putative binding sites for mir-206 in the MET 3' untranslated region. Ectopic expression of mir-206 caused loss of MET expression, induction of skeletal muscle differentiation markers, loss of cell proliferation, and decreased tumor burden in mouse RMS xenografts [97, 98]. The mechanism behind the loss of mir- 1 and mir-206 in RMS remains to be determined, but its potential to downregulate therapeutic targets like MET may hold promise for RMS treatments in the future.

\section{Therapeutic Potential for RTK Inhibition in Rhabdomyosarcoma}

As druggable receptors at the plasma membrane, RTKs have been the focus of intense basic and pharmacologic research.
Small molecule inhibitors, ligand-neutralizing agents, and monoclonal receptor-blocking antibodies have been generated for many of the RTKs expressed in RMS. However, it is not likely that all of the RTKs in RMS will survive the tests of robust preclinical testing and be evaluated in clinical trials. Therefore, determining which target(s) are the most promising and worthy of clinical trial assignment will be critical. As described below, understanding their mechanisms of upregulation, acquired resistance, and pathway crosstalk will be key to determining how to pharmacologically exploit RTK signaling in RMS.

RTKs are only one of numerous and diverse signaling pathways upregulated in cancer, so identifying the RTKs upregulated in RMS is only a starting point to determine their potential as therapeutic targets. In many cases, blockade of an upregulated RTK will cause cytostatic growth inhibition but not eliminate the cancer cells completely, leading to emergence of resistant clones and refractory disease. However, if the cells have become dependent on a particular RTK signaling pathway for survival, so-called "oncogene addiction" [99], blockade of these pathways should be more effective in disease eradication. The challenge then becomes determining which RTKs confer oncogene addiction.

Another possibility is the presence of activating mutations in RTKs. RTKs containing an activating mutation are much more sensitive to inhibitors targeting that RTK than cells or tumors with a wild-type RTK. An example of this phenomenon was observed in non-small cell lung carcinoma. In clinical trials of EGFR inhibitors, only $10 \%$ of patients responded to treatment. Upon further investigation, it was found that the responding patients harbored somatic, activating EGFR mutations [100]. Similarly, in PPTP screening, Kasumi-1 cells (which contain an activating c-KIT mutation) were found to be particularly sensitive to sorafenib [101]. To date, FGFR4 is the only RTK known to have an activating mutation in RMS [92]. Deep sequencing of RTKs implicated in RMS will need to be done to address the possibility that other RTKs are mutated in RMS. A second possibility is genomic amplification or deletion or sheer upregulation of RTKs or their signaling components. This has already proven important in our understanding of IGF-1R in RMS, as the loss of imprinting of the IGF-2 gene, or higher expression levels of IGF-1R, lead to oncogene dependence even in the absence of an activating mutation and confer sensitivity to RTK blockade $[13,16]$. Similarly, wild-type EGFR expression is upregulated in RMS cells. Although inhibition of EGFR does not appear to be a promising candidate for monotherapy, recent studies have suggested that EGFR could be used in targeted immunotherapy applications [102]. In sum, understanding the underlying genetic changes as well as utilizing upregulation of RTKs through novel treatments will guide future RMS therapies.

A drawback of targeted therapies is the ability of tumor cells to adapt and acquire resistance. Through further upregulation of the therapeutic target, mutation of the therapeutic target, or upregulation of a compensating RTK or signaling pathway, cancer cells can rapidly adjust to promote tumor cell survival [103]. For example, in the case of IGF-1R blockade, RMS cells resistant to IGF-1R small 


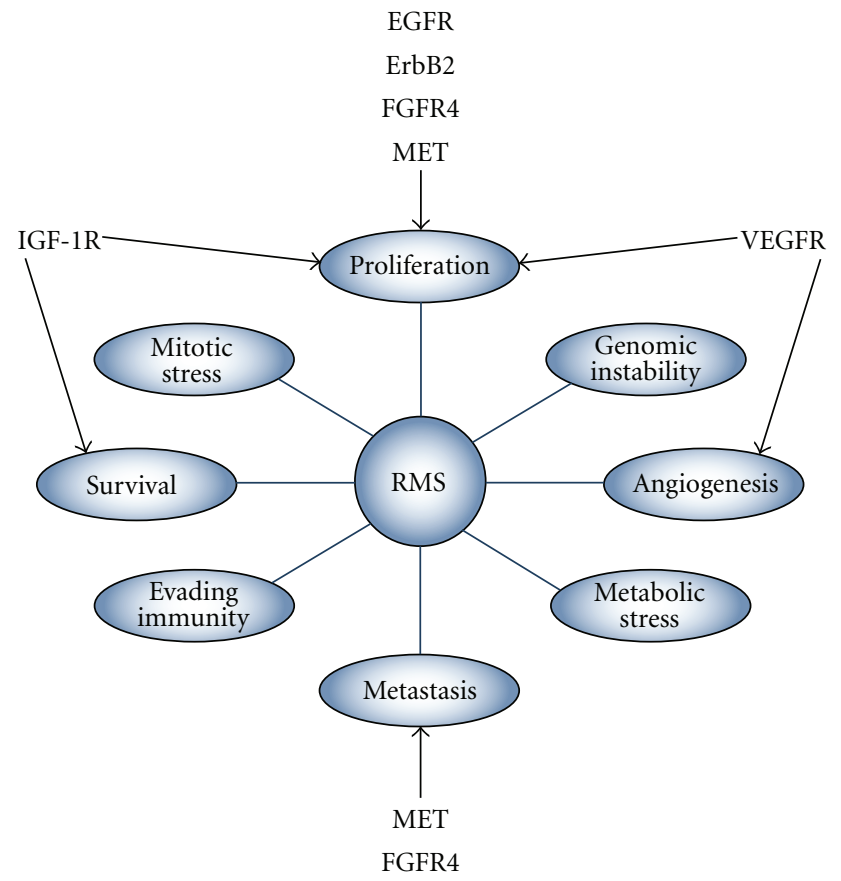

FIGURE 2: RTKs associated with RMS and their known roles in RMS tumorigenesis or progression.

molecule inhibitors were found to have increased expression of EGFR when compared to those cells that were sensitive. To this end, dual treatment with IGF-1R and EGFR inhibition increased the antitumor effect in RMS mouse xenograft models [24]. Understanding how and if RMS cells adapt to targeted therapies will be critical for successful treatment options.

Although induction of resistance may pose a problem for targeted therapy in RMS, crosstalk within signaling pathways could provide a way to exploit RTK inhibition. For example, the IGF-1R and VEGFR pathways exhibit crosstalk in RMS, and by experimentally inhibiting IGF$1 \mathrm{R}$ signaling, VEGF secretion is reduced [28]. Thus, IGF$1 \mathrm{R}$ blockade has the potential to thwart both IGF-1R and VEGFR pathways. In addition, many RTKs utilize redundant downstream signaling components. Targeting more than one RTK through multiple individual inhibitors, or using a less specific inhibitor to block several RTKs simultaneously, may prove beneficial by strong inhibition of signaling at a common node. Through a systematic and comprehensive analysis of other as yet undescribed crosstalk mechanisms in RMS, these dependencies can be identified and provide the basis for further preclinical testing.

In addition to the theoretical attraction of combination therapy on blocking signaling pathways, dual or multiple inhibition of RTKs may offer beneficial effects in inhibiting the unique tumorigenic properties of cancer cells. The "hallmarks of cancer" as defined by Hanahan and Weinberg [104], and further classified by Negrini et al. [105], represent specific tumorigenic properties of the cancer cell, as shown in Figure 2. The RTKs we have described impact various cancer cell characteristics. Through targeting of individual RTKs, therapeutic intervention could inhibit distinct malignant properties. When blocked in combination, inhibition of multiple RTKs could have a profound effect on tumor growth and progression. Realistically, these positive outcomes on tumor inhibition may be offset by increased incidence of toxicity and side effects. Therefore, until both preclinical and clinical studies address these issues, combination targeted therapy will pose a sizeable challenge for researchers.

\section{Prioritization of Therapeutic Targets}

One of the most daunting challenges for pediatric oncology clinical trial design is how to identify the strongest therapeutic candidates to pursue. Because of the limited number of pediatric patients, only the most promising agents under development as cancer treatment should be evaluated in a clinical trial setting. As mentioned above, the PPTP provides a preclinical platform to screen an experimental compound against many types of pediatric cancers. To be considered for a PPTP screen, there must be significant rationale for the proposed agent in pediatric cancers, including the mechanism of action and in vitro and in vivo efficacy. In some cases, evidence from pediatric preclinical models or adult clinical trials is available, providing pharmacokinetic and dosing data. These cases may receive priority, as they expedite some of the issues addressed in early clinical trials. In terms of prioritization of RTK targets, there is a need to understand the genetic foundation behind activation of specific RTK signaling pathways in RMS cells. Genetic screening of RTKs for mutations or analysis of downstream signaling pathways may provide insight into which therapeutic candidates could have the most profound effects on RMS cells. Clearly, both large scale screens and mechanistic validation will be necessary to prioritize the many candidates. 
There are still numerous RTK targets that could be utilized for RMS therapy and warrant further study to provide additional treatment opportunities. Additional study of these targets in preclinical models will be necessary to advance their use to clinical trials, either as single targeting agents, multiple targeting agents, or single targeting agents in combination with cytotoxic therapy. As we expand our knowledge of how RTKs function individually or together, the potential for utilizing RTK inhibition could be a turning point in a new era of targeted therapy for RMS. The future of RMS therapies holds promise and will provide improved options for RMS patients, including those in high risk groups.

\section{Acknowledgments}

The authors were supported by R01 CA122706 (to C. M. Linardic) and T32 CA059365 (to L. E. S. Crose).

\section{References}

[1] D. M. Parham, "Pathologic classification of rhabdomyosarcomas and correlations with molecular studies," Modern Pathology, vol. 14, no. 5, pp. 506-514, 2001.

[2] S. Ognjanovic, A. M. Linabery, B. Charbonneau, and J. A. Ross, "Trends in childhood rhabdomyosarcoma incidence and survival in the United States, 1975-2005," Cancer, vol. 115, no. 18, pp. 4218-4226, 2009.

[3] J. Sumegi, R. Streblow, R. W. Frayer et al., "Recurrent t(2;2) and $\mathrm{t}(2 ; 8)$ translocations in rhabdomyosarcoma without the canonical PAX-FOXO1 fuse PAX3 to members of the nuclear receptor transcriptional coactivator family," Genes Chromosomes and Cancer, vol. 49, no. 3, pp. 224-236, 2010.

[4] P. H. B. Sorensen, J. C. Lynch, S. J. Qualman et al., "PAX3-FKHR and PAX7-FKHR gene fusions are prognostic indicators in alveolar rhabdomyosarcoma: a report from the Children's Oncology Group," Journal of Clinical Oncology, vol. 20, no. 11, pp. 2672-2679, 2002.

[5] E. Davicioni, J. R. Anderson, J. D. Buckley, W. H. Meyer, and T. J. Triche, "Gene expression profiling for survival prediction in pediatric rhabdomyosarcomas: a report from the children's oncology group," Journal of Clinical Oncology, vol. 28, no. 7, pp. 1240-1246, 2010.

[6] D. Williamson, E. Missiaglia, A. de Reynies et al., "Fusion gene-negative alveolar rhabdomyosarcoma is clinically and molecularly indistinguishable from embryonal rhabdomyosarcoma," Journal of Clinical Oncology, vol. 28, no. 13, pp. 2151-2158, 2010.

[7] H. P. McDowell, "Update on childhood rhabdomyosarcoma," Archives of Disease in Childhood, vol. 88, no. 4, pp. 354-357, 2003.

[8] J. P. Liu, J. Baker, A. S. Perkins, E. J. Robertson, and A. Efstratiadis, "Mice carrying null mutations of the genes encoding insulin-like growth factor I (Igf-1) and type 1 IGF receptor (Igf1r)," Cell, vol. 75, no. 1, pp. 59-72, 1993.

[9] J. R. Florini, D. Z. Ewton, and S. A. Coolican, "Growth hormone and the insulin-like growth factor system in myogenesis," Endocrine Reviews, vol. 17, no. 5, pp. 481-517, 1996.

[10] J. Dupont and M. Holzenberger, "Biology of insulin-like growth factors in development," Birth Defects Research Part C, vol. 69, no. 4, pp. 257-271, 2003.
[11] J. Scott, J. Cowell, and M. E. Robertson, "Insulin-like growth factor-II gene expression in Wilms' tumour and embryonic tissues," Nature, vol. 317, no. 6034, pp. 260-262, 1985.

[12] O. M. El-Badry, C. Minniti, E. C. Kohn, P. J. Houghton, W. H. Daughaday, and L. J. Helman, "Insulin-like growth factor II acts as an autocrine growth and motility factor in human rhabdomyosarcoma tumors," Cell Growth and Differentiation, vol. 1, no. 7, pp. 325-331, 1990.

[13] S. Zhan, D. N. Shapiro, and L. J. Helman, "Activation of an imprinted allele of the insulin-like growth factor II gene implicated in rhabdomyosarcoma," Journal of Clinical Investigation, vol. 94, no. 1, pp. 445-448, 1994.

[14] P. V. Pedone, R. Tirabosco, A. O. Cavazzana et al., "Monoand bi-allelic expression of insulin-like growth factor II gene in human muscle tumors," Human Molecular Genetics, vol. 3, no. 7, pp. 1117-1121, 1994.

[15] L. Cao, Y. Yu, S. Bilke et al., "Genome-wide identification of PAX3-FKHR binding sites in rhabdomyosarcoma reveals candidate target genes important for development and cancer," Cancer Research, vol. 70, no. 16, pp. 6497-6508, 2010.

[16] L. Cao, Y. Yu, I. Darko et al., "Addiction to elevated insulinlike growth factor I receptor and initial modulation of the AKT pathway define the responsiveness of rhabdomyosarcoma to the targeting antibody," Cancer Research, vol. 68, no. 19, pp. 8039-8048, 2008.

[17] M. B. Dilling, P. Dias, D. N. Shapiro, G. S. Germain, R. K. Johnson, and P. J. Houghton, "Rapamycin selectively inhibits the growth of childhood rhabdomyosarcoma cells through inhibition of signaling via the type I insulin-like growth factor receptor," Cancer Research, vol. 54, no. 4, pp. 903-907, 1994.

[18] D. N. Shapiro, B. G. Jones, L. H. Shapiro, P. Dias, and P. J. Houghton, "Antisense-mediated reduction in insulin-like growth factor-I receptor expression suppresses the malignant phenotype of a human alveolar rhabdomyosarcoma," Journal of Clinical Investigation, vol. 94, no. 3, pp. 1235-1242, 1994.

[19] T. Kalebic, M. Tsokos, and L. J. Helman, "In vivo treatment with antibody against IGF-1 receptor suppresses growth of human rhabdomyosarcoma and down-regulates p34(cdc2)," Cancer Research, vol. 54, no. 21, pp. 5531-5534, 1994.

[20] T. Kalebic, V. Blakesley, C. Slade, S. Plasschaert, D. Leroith, and J. Lee Helman, "Expression of a kinase-deficient IGFI-R suppresses tumorigenicity of rhabdomyosarcoma cells constitutively expressing a wild type IGF-I-R," International Journal of Cancer, vol. 76, no. 2, pp. 223-227, 1998.

[21] E. K. Maloney, J. L. McLaughlin, N. E. Dagdigian et al., "An anti-insulin-like growth factor I receptor antibody that is a potent inhibitor of cancer cell proliferation," Cancer Research, vol. 63, no. 16, pp. 5073-5083, 2003.

[22] K. Scotlandi, M. C. Manara, G. Nicoletti et al., "Antitumor activity of the insulin-like growth factor-I receptor kinase inhibitor NVP-AEW541 in musculoskeletal tumors," Cancer Research, vol. 65, no. 9, pp. 3868-3876, 2005.

[23] J. M. Carboni, M. Wittman, Z. Yang et al., "BMS-754807, a small molecule inhibitor of insulin-like growth factor1R/IR," Molecular Cancer Therapeutics, vol. 8, no. 12, pp. 3341-3349, 2009.

[24] F. Huang, A. Greer, W. Hurlburt et al., "The mechanisms of differential sensitivity to an insulin-like growth factor-1 receptor inhibitor (BMS-536924) and rationale for combining with EGFR/HER2 inhibitors," Cancer Research, vol. 69, no. 1, pp. 161-170, 2009.

[25] P. J. Houghton, C. L. Morton, R. Gorlick et al., "Initial testing of a monoclonal antibody (IMC-A12) against IGF-1R by the 
pediatric preclinical testing program," Pediatric Blood and Cancer, vol. 54, no. 7, pp. 921-926, 2010.

[26] H. Hosoi, M. B. Dilling, T. Shikata et al., "Rapamycin causes poorly reversible inhibition of mTOR and induces p53independent apoptosis in human rhabdomyosarcoma cells," Cancer Research, vol. 59, no. 4, pp. 886-894, 1999.

[27] L. S. Harrington, G. M. Findlay, A. Gray et al., "The TSC1-2 tumor suppressor controls insulin-PI3K signaling via regulation of IRS proteins," Journal of Cell Biology, vol. 166, no. 2, pp. 213-223, 2004.

[28] R. T. Kurmasheva, L. Dudkin, C. Billups, L. V. Debelenko, C. L. Morton, and P. J. Houghton, "The insulin-like growth factor-1 receptor-targeting antibody, CP-751,871, suppresses tumor-derived VEGF and synergizes with rapamycin in models of childhood sarcoma," Cancer Research, vol. 69, no. 19 , pp. 7662-7671, 2009.

[29] X. Wan, B. Harkavy, N. Shen, P. Grohar, and L. J. Helman, "Rapamycin induces feedback activation of Akt signaling through an IGF-1R-dependent mechanism," Oncogene, vol. 26, no. 13, pp. 1932-1940, 2007.

[30] F. Bladt, D. Riethmacher, S. Isenmann, A. Aguzzi, and C. Birchmeier, "Essential role for the c-met receptor in the migration of myogenic precursor cells into the limb bud," Nature, vol. 376, no. 6543, pp. 768-771, 1995.

[31] R. Gal-Levi, Y. Leshem, S. Aoki, T. Nakamura, and O. Halevy, "Hepatocyte growth factor plays a dual role in regulating skeletal muscle satellite cell proliferation and differentiation," Biochimica et Biophysica Acta, vol. 1402, no. 1, pp. 39-51, 1998.

[32] S. Anastasi, S. Giordano, O. Sthandier et al., "A natural hepatocyte growth factor/scatter factor autocrine loop in myoblast cells and the effect of the constitutive met kinase activation on myogenic differentiation," Journal of Cell Biology, vol. 137, no. 5, pp. 1057-1068, 1997.

[33] K. Jankowski, M. Kucia, M. Wysoczynski et al., "Both hepatocyte growth factor (HGF) and stromal-derived factor1 regulate the metastatic behavior of human rhabdomyosarcoma cells, but only HGF enhances their resistance to radiochemotherapy," Cancer Research, vol. 63, no. 22, pp. 7926-7935, 2003.

[34] R. Ferracini, M. Olivero, M. F. Di Renzo et al., "Retrogenic expression of the MET proto-oncogene correlates with the invasive phenotype of human rhabdomyosarcomas," Oncogene, vol. 12, no. 8, pp. 1697-1705, 1996.

[35] E. Lukasiewicz, K. Miekus, J. Kijowski et al., "Inhibition of rhabdomyosarcoma's metastatic behavior through downregulation of MET receptor signaling," Folia Histochemica et Cytobiologica, vol. 47, no. 3, pp. 485-489, 2009.

[36] E. Lesko, J. Gozdzik, J. Kijowski, B. Jenner, O. Wiecha, and M. Majka, "HSP90 antagonist, geldanamycin, inhibits proliferation, induces apoptosis and blocks migration of rhabdomyosarcoma cells in vitro and seeding into bone marrow in vivo," Anti-Cancer Drugs, vol. 18, no. 10, pp. 1173-1181, 2007.

[37] F. Diomedi-Camassei, H. P. McDowell, M. A. De loris et al., "Clinical significance of CXC chemokine receptor-4 and c-Met in childhood rhabdomyosarcoma," Clinical Cancer Research, vol. 14, no. 13, pp. 4119-4127, 2008.

[38] E. Bober, T. Franz, H. H. Arnold, P. Gruss, and P. Tremblay, "Pax-3 is required for the development of limb muscles: a possible role for the migration of dermomyotomal muscle progenitor cells," Development, vol. 120, no. 3, pp. 603-612, 1994.
[39] J. A. Epstein, D. N. Shapiro, J. Cheng, P. Y. P. Lam, and R. L. Maas, "PAX3 modulates expression of the c-met receptor during limb muscle development," Proceedings of the National Academy of Sciences of the United States of America, vol. 93, no. 9, pp. 4213-4218, 1996.

[40] J. P. Ginsberg, R. J. Davis, J. L. Bennicelli, L. E. Nauta, and F. G. Barr, "Up-regulation of MET but not neural cell adhesion molecule expression by the PAX3-FKHR fusion protein in alveolar rhabdomyosarcoma," Cancer Research, vol. 58, no. 16, pp. 3542-3546, 1998.

[41] N. Tiffin, R. D. Williams, J. Shipley, and K. Pritchard-Jones, "PAX7 expression in embryonal rhabdomyosarcoma suggests an origin in muscle satellite cells," British Journal of Cancer, vol. 89, no. 2, pp. 327-332, 2003.

[42] R. Taulli, C. Scuoppo, F. Bersani et al., "Validation of met as a therapeutic target in alveolar and embryonal rhabdomyosarcoma," Cancer Research, vol. 66, no. 9, pp. 4742-4749, 2006.

[43] H. Takayama, W. J. Larochelle, R. Sharp et al., "Diverse tumorigenesis associated with aberrant development in mice overexpressing hepatocyte growth factor/scatter factor," Proceedings of the National Academy of Sciences of the United States of America, vol. 94, no. 2, pp. 701-706, 1997.

[44] R. Sharp, J. A. Recio, C. Jhappan et al., "Synergism between INK4a/ARF inactivation and aberrant HGF/SF signaling in rhabdomyosarcomagenesis," Nature Medicine, vol. 8, no. 11, pp. 1276-1280, 2002.

[45] F. Relaix, M. Polimeni, D. Rocancourt, C. Ponzetto, B. W. Schäfer, and M. Buckingham, "The transcriptional activator PAX3-FKHR rescues the defects of PAX3 mutant mice but induces a myogenic gain-of-function phenotype with ligandindependent activation of Met signaling in vivo," Genes and Development, vol. 17, no. 23, pp. 2950-2965, 2003.

[46] C. Keller, B. R. Arenkiel, C. M. Coffin, N. El-Bardeesy, R. A. DePinho, and M. R. Capecchi, "Alveolar rhabdomyosarcomas in conditional PAX3:Fkhr mice: cooperativity of Ink4a/ARF and Trp53 loss of function," Genes and Development, vol. 18, no. 21, pp. 2614-2626, 2004.

[47] G. Sithanandam and L. M. Anderson, "The ERBB3 receptor in cancer and cancer gene therapy," Cancer Gene Therapy, vol. 15, no. 7, pp. 413-448, 2008.

[48] M. Horikawa, S. Higashiyama, S. Nomura, Y. Kitamura, M. Ishikawa, and N. Taniguchi, "Upregulation of endogenous heparin-binding EGF-like growth factor and its role as a survival factor in skeletal myotubes," FEBS Letters, vol. 459, no. 1, pp. 100-104, 1999.

[49] P. M. Harari, "Epidermal growth factor receptor inhibition strategies in oncology," Endocrine-Related Cancer, vol. 11, no. 4, pp. 689-708, 2004.

[50] J. M. Maris, J. Courtright, P. J. Houghton et al., "Initial testing of the VEGFR inhibitor AZD2171 by the Pediatric Preclinical Testing Program," Pediatric Blood and Cancer, vol. 50, no. 3, pp. 581-587, 2008.

[51] C. De Giovanni, C. Melani, P. Nanni et al., "Redundancy of autocrine loops in human rhabdomyosarcoma cells: induction of differentiation by suramin," British Journal of Cancer, vol. 72, no. 5, pp. 1224-1229, 1995.

[52] C. Ricci, L. Landuzzi, I. Rossi et al., "Expression of HER/erbB family of receptor tyrosine kinases and induction of differentiation by glial growth factor 2 in human rhabdomyosarcoma cells," International Journal of Cancer, vol. 87, no. 1, pp. 2936, 2000.

[53] P. M. Armistead, J. Salganick, J. S. Roh et al., "Expression of receptor tyrosine kinases and apoptotic molecules in 
rhabdomyosarcoma: correlation with overall survival in 105 patients," Cancer, vol. 110, no. 10, pp. 2293-2303, 2007.

[54] B. Grass, M. Wachtel, S. Behnke, I. Leuschner, F. K. Niggli, and B. W. Schäfer, "Immunohistochemical detection of EGFR, fibrillin-2, P-cadherin and AP2 $\beta$ as biomarkers for rhabdomyosarcoma diagnostics," Histopathology, vol. 54, no. 7, pp. 873-879, 2009.

[55] R. Ganti, S. X. Skapek, J. Zhang et al., "Expression and genomic status of EGFR and ErbB-2 in alveolar and embryonal rhabdomyosarcoma," Modern Pathology, vol. 19, no. 9, pp. 1213-1220, 2006.

[56] M. Wachtel, T. Runge, I. Leuschner et al., "Subtype and prognostic classification of rhabdomyosarcoma by immunohistochemistry," Journal of Clinical Oncology, vol. 24, no. 5, pp. 816-822, 2006.

[57] C. R. de Andrade, A. Takahama Junior, I. N. Nishimoto, L. P. Kowalski, and M. A. Lopes, "Rhabdomyosarcoma of the head and neck: a clinicopathological and immunohistochemical analysis of 29 cases," Brazilian Dental Journal, vol. 21, no. 1, pp. 68-73, 2010.

[58] C. De Giovanni, L. Landuzzi, F. Frabetti et al., "Antisense epidermal growth factor receptor transfection impairs the proliferative ability of human rhabdomyosarcoma cells," Cancer Research, vol. 56, no. 17, pp. 3898-3901, 1996.

[59] P. Nanni, G. Nicoletti, C. De Giovanni et al., "Development of rhabdomyosarcoma in HER-2/neu transgenic p53 mutant mice," Cancer Research, vol. 63, no. 11, pp. 2728-2732, 2003.

[60] S. Croci, G. Nicoletti, L. Landuzzi et al., "Immunological prevention of a multigene cancer syndrome," Cancer Research, vol. 64, no. 22, pp. 8428-8434, 2004.

[61] B. B. Freeman III, N. C. Daw, J. R. Geyer, W. L. Furman, and C. F. Stewart, "Evaluation of gefitinib for treatment of refractory solid tumors and central nervous system malignancies in pediatric patients," Cancer Investigation, vol. 24, no. 3, pp. 310-317, 2006.

[62] R. I. Jakacki, M. Hamilton, R. J. Gilbertson et al., "Pediatric phase I and pharmacokinetic study of erlotinib followed by the combination of erlotinib and temozolomide: a children's oncology group phase I consortium study," Journal of Clinical Oncology, vol. 26, no. 30, pp. 4921-4927, 2008.

[63] J. Andrae, R. Gallini, and C. Betsholtz, "Role of plateletderived growth factors in physiology and medicine," Genes and Development, vol. 22, no. 10, pp. 1276-1312, 2008.

[64] T. Fiaschi, P. Chiarugi, F. Buricchi et al., "Down-regulation of platelet-derived growth factor receptor signaling during myogenesis," Cellular and Molecular Life Sciences, vol. 60, no. 12 , pp. 2721-2735, 2003

[65] S. E. Webb and K. K. H. Lee, "Effect of platelet-derived growth factor isoforms on the migration of mouse embryo limb myogenic cells," International Journal of Developmental Biology, vol. 41, no. 4, pp. 597-605, 1997.

[66] Z. Yablonka-Reuveni, T. M. Balestreri, and D. F. BowenPope, "Regulation of proliferation and differentiation of myoblasts derived from adult mouse skeletal muscle by specific isoforms of PDGF," Journal of Cell Biology, vol. 111, no. 4, pp. 1623-1629, 1990.

[67] R. Malik, M. Gope, R. B. Womer et al., "Structure and expression of the $\beta$-platelet-derived growth factor receptor gene in human tumor cell lines," Cancer Research, vol. 51, no. 20, pp. 5626-5631, 1991.

[68] H. P. McDowell, D. Meco, A. Riccardi et al., "Imatinib mesylate potentiates topotecan antitumor activity in rhabdomyosarcoma preclinical models," International Journal of Cancer, vol. 120, no. 5, pp. 1141-1149, 2007.
[69] U. McDermott, R. Y. Ames, A. J. Iafrate et al., "Liganddependent platelet-derived growth factor receptor (PDGFR)$\alpha$ activation sensitizes rare lung cancer and sarcoma cells to PDGFR kinase inhibitors," Cancer Research, vol. 69, no. 9, pp. 3937-3946, 2009.

[70] J. A. Epstein, B. Song, M. Lakkis, and C. Wang, "Tumorspecific PAX3-FKHR transcription factor, but not PAX3, activates the platelet-derived growth factor alpha receptor," Molecular and Cellular Biology, vol. 18, no. 7, pp. 4118-4130, 1998.

[71] E. Taniguchi, K. Nishijo, A. T. McCleish et al., "PDGFRA is a therapeutic target in alveolar rhabdomyosarcoma," Oncogene, vol. 27, no. 51, pp. 6550-6560, 2008.

[72] M. C. Blandford, F. G. Barr, J. C. Lynch, R. L. Randall, S. J. Qualman, and C. Keller, "Rhabdomyosarcomas utilize developmental, myogenic growth factors for disease advantage: a report from the children's oncology group," Pediatric Blood and Cancer, vol. 46, no. 3, pp. 329-338, 2006.

[73] R. Chugh, J. K. Wathen, R. G. Maki et al., "Phase II multicenter trial of imatinib in 10 histologic subtypes of sarcoma using a bayesian hierarchical statistical model," Journal of Clinical Oncology, vol. 27, no. 19, pp. 3148-3153, 2009.

[74] P. Carmeliet and R. K. Jain, "Angiogenesis in cancer and other diseases," Nature, vol. 407, no. 6801, pp. 249-257, 2000.

[75] A. Germani, A. Di Carlo, A. Mangoni et al., "Vascular endothelial growth factor modulates skeletal myoblast function," American Journal of Pathology, vol. 163, no. 4, pp. 1417-1428, 2003.

[76] M. F. W. Gee, R. Tsuchida, C. Eichler-Jonsson, B. Das, S. Baruchel, and D. Malkin, "Vascular endothelial growth factor acts in an autocrine manner in rhabdomyosarcoma cell lines and can be inhibited with all-trans-retinoic acid," Oncogene, vol. 24, no. 54, pp. 8025-8037, 2005.

[77] R. T. Kurmasheva, F. C. Harwood, and P. J. Houghton, "Differential regulation of vascular endothelial growth factor by Akt and mammalian target of rapamycin inhibitors in cell lines derived from childhood solid tumors," Molecular Cancer Therapeutics, vol. 6, no. 5, pp. 1620-1628, 2007.

[78] R. A. Brekken, J. P. Overholser, V. A. Stastny, J. Waltenberger, J. D. Minna, and P. E. Thorpe, "Selective inhibition of vascular endothelial growth factor (VEGF) receptor 2 (KDR/Flk-1) activity by a monoclonal anti-VEGF antibody blocks tumor growth in mice," Cancer Research, vol. 60, no. 18, pp. 5117$5124,2000$.

[79] H. P. Gerber, J. Kowalski, D. Sherman, D. A. Eberhard, and N. Ferrara, "Complete inhibition of rhabdomyosarcoma xenograft growth and neovascularization requires blockade of both tumor and host vascular endothelial growth factor," Cancer Research, vol. 60, no. 22, pp. 6253-6258, 2000.

[80] J. Holash, S. Davis, N. Papadopoulos et al., "VEGF-Trap: a VEGF blocker with potent antitumor effects," Proceedings of the National Academy of Sciences of the United States of America, vol. 99, no. 17, pp. 11393-11398, 2002.

[81] J. N. Rich, S. Sathornsumetee, S. T. Keir et al., "ZD6474, a novel tyrosine kinase inhibitor of vascular endothelial growth factor receptor and epidermal growth factor receptor, inhibits tumor growth of multiple nervous system tumors," Clinical Cancer Research, vol. 11, no. 22, pp. 8145-8157, 2005.

[82] R. Tsuchida, B. Das, H. Yeger et al., "Cisplatin treatment increases survival and expansion of a highly tumorigenic side-population fraction by upregulating VEGF/Flt1 autocrine signaling," Oncogene, vol. 27, no. 28, pp. 39233934, 2008. 
[83] V. P. Eswarakumar, I. Lax, and J. Schlessinger, "Cellular signaling by fibroblast growth factor receptors," Cytokine and Growth Factor Reviews, vol. 16, no. 2, pp. 139-149, 2005.

[84] PO. Zhao, G. Caretti, S. Mitchell et al., "Fgfr4 is required for effective muscle regeneration in vivo delineation of a MyoDTead2-Fgfr4 transcriptional pathway," Journal of Biological Chemistry, vol. 281, no. 1, pp. 429-438, 2006.

[85] I. Marics, F. Padilla, J. F. Guillemot, M. Scaal, and C. Marcelle, "FGFR4 signaling is a necessary step in limb muscle differentiation," Development, vol. 129, no. 19, pp. 45594569, 2002.

[86] S. Pizette, F. Coulier, D. Birnbaum, and O. Delapeyrière, "FGF6 modulates the expression of fibroblast growth factor receptors and myogenic genes in muscle cells," Experimental Cell Research, vol. 224, no. 1, pp. 143-151, 1996.

[87] M. Goldstein, I. Meller, and A. Orr-Urtreger, "FGFR1 over-expression in primary rhabdomyosarcoma tumors is associated with hypomethylation of a $5^{\prime} \mathrm{CpG}$ island and abnormal expression of the AKT1, NOG, and BMP4 genes," Genes Chromosomes and Cancer, vol. 46, no. 11, pp. 10281038, 2007.

[88] M. Hirotsu, T. Setoguchi, Y. Matsunoshita et al., "Tumour formation by single fibroblast growth factor receptor 3positive rhabdomyosarcoma-initiating cells," British Journal of Cancer, vol. 101, no. 12, pp. 2030-2037, 2009.

[89] L. Schweigerer, G. Neufeld, and A. Mergia, "Basic fibroblast growth factor in human rhabdomyosarcoma cells: implications for the proliferation and neovascularization of myoblast-derived tumors," Proceedings of the National Academy of Sciences of the United States of America, vol. 84, no. 3, pp. 842-846, 1987.

[90] S. J. Yu, L. Zheng, M. Ladanyi, S. L. Asa, and S. Ezzat, "Sp1mediated transcriptional control of fibroblast growth factor receptor 4 in sarcomas of skeletal muscle lineage," Clinical Cancer Research, vol. 10, no. 19, pp. 6750-6758, 2004.

[91] J. Khan, J. S. Wei, M. Ringner et al., "Classification and diagnostic prediction of cancers using gene expression profiling and artificial neural networks," Nature Medicine, vol. 7, no. 6, pp. 673-679, 2001.

[92] J. G. Taylor, A. T. Cheuk, P. S. Tsang et al., "Identification of FGFR4-activating mutations in human rhabdomyosarcomas that promote metastasis in xenotransplanted models," Journal of Clinical Investigation, vol. 119, no. 11, pp. 3395-3407, 2009.

[93] T. D. Barber, M. C. Barber, O. Tomescu, F. G. Barr, S. Ruben, and T. B. Friedman, "Identification of target genes regulated by $P A X 3$ and $P A X 3-F K H R$ in embryogenesis and alveolar rhabdomyosarcoma," Genomics, vol. 79, no. 3, pp. 278-284, 2002.

[94] Y. Chen, J. Takita, M. Mizuguchi et al., "Mutation and expression analyses of the MET and CDKN2A in rhabdomyosarcoma with emphasis on MET overexpression," Genes Chromosomes and Cancer, vol. 46, no. 4, pp. 348-358, 2007.

[95] H. Werner, E. Karnieli, F. J. Rauscher, and D. LeRoith, "Wildtype and mutant p53 differentially regulate transcription of the insulin-like growth factor I receptor gene," Proceedings of the National Academy of Sciences of the United States of America, vol. 93, no. 16, pp. 8318-8323, 1996.

[96] K. K. Hak, S. L. Yong, U. Sivaprasad, A. Malhotra, and A. Dutta, "Muscle-specific microRNA miR-206 promotes muscle differentiation," Journal of Cell Biology, vol. 174, no. 5, pp. 677-687, 2006.
[97] R. Taulli, F. Bersani, V. Foglizzo et al., "The musclespecific microRNA miR-206 blocks human rhabdomyosarcoma growth in xenotransplanted mice by promoting myogenic differentiation," Journal of Clinical Investigation, vol. 119, no. 8, pp. 2366-2378, 2009.

[98] D. Yan, X. D. Dong, X. Chen et al., "MicroRNA-1/206 targets c-met and inhibits rhabdomyosarcoma development," Journal of Biological Chemistry, vol. 284, no. 43, pp. 2959629604, 2009.

[99] I. B. Weinstein and A. Joe, "Oncogene addiction," Cancer Research, vol. 68, no. 9, pp. 3077-3080, 2008.

[100] T. J. Lynch, D. W. Bell, R. Sordella et al., "Activating mutations in the epidermal growth factor receptor underlying responsiveness of non-small-cell lung cancer to gefitinib," New England Journal of Medicine, vol. 350, no. 21, pp. 21292139, 2004.

[101] S. T. Keir, J. M. Maris, R. Lock et al., "Initial testing (stage 1) of the multi-targeted kinase inhibitor sorafenib by the pediatric preclinical testing program," Pediatric Blood and Cancer, vol. 55, no. 6, pp. 1126-1133, 2010.

[102] D. Herrmann, G. Seitz, S. W. Warmann, M. Bonin, J. Fuchs, and S. Armeanu-Ebinger, "Cetuximab promotes immunotoxicity against rhabdomyosarcoma in vitro," Journal of Immunotherapy, vol. 33, no. 3, pp. 279-286, 2010.

[103] J. R. Sierra, V. Cepero, and S. Giordano, "Molecular mechanisms of acquired resistance to tyrosine kinase targeted therapy," Molecular Cancer, vol. 9, article no .75, 2010.

[104] D. Hanahan and R. A. Weinberg, "The hallmarks of cancer," Cell, vol. 100, no. 1, pp. 57-70, 2000.

[105] S. Negrini, V. G. Gorgoulis, and T. D. Halazonetis, "Genomic instability an evolving hallmark of cancer," Nature Reviews Molecular Cell Biology, vol. 11, no. 3, pp. 220-228, 2010. 


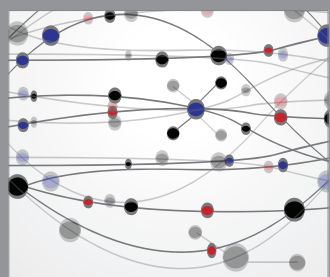

The Scientific World Journal
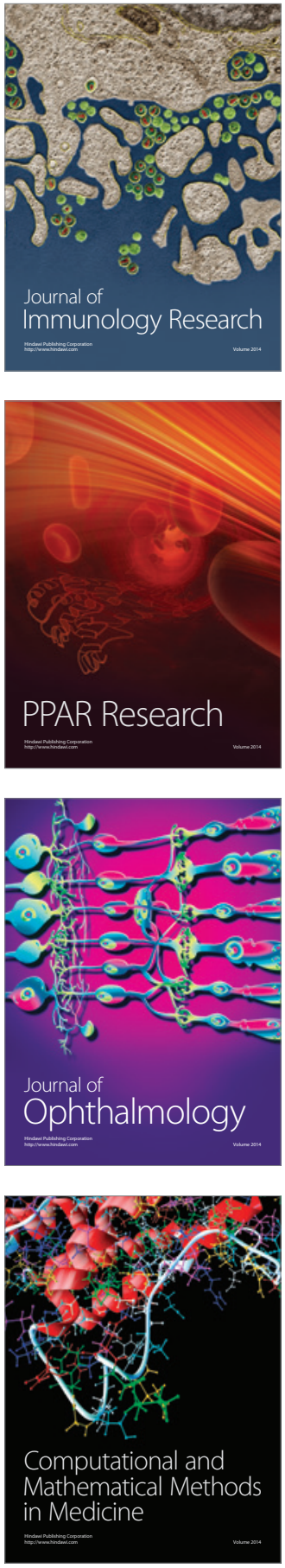

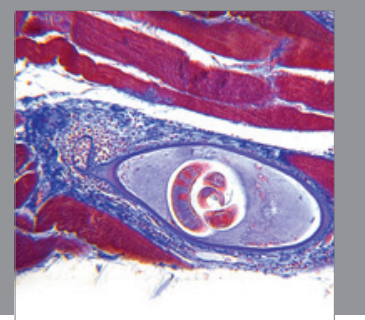

Gastroenterology

Research and Practice
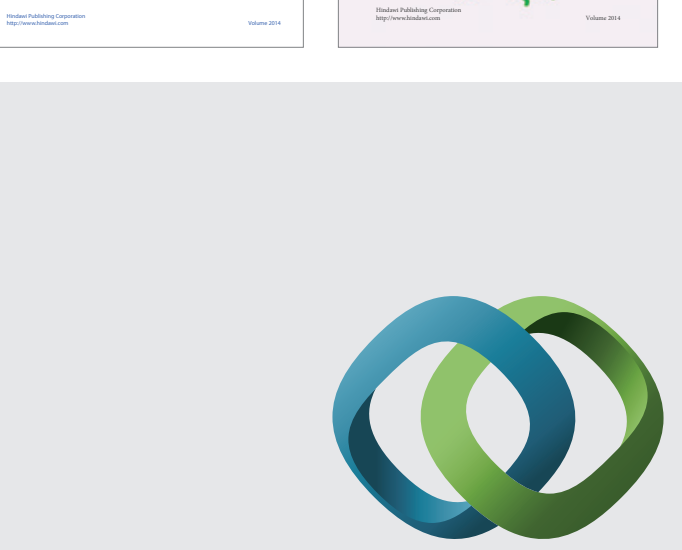

\section{Hindawi}

Submit your manuscripts at

http://www.hindawi.com
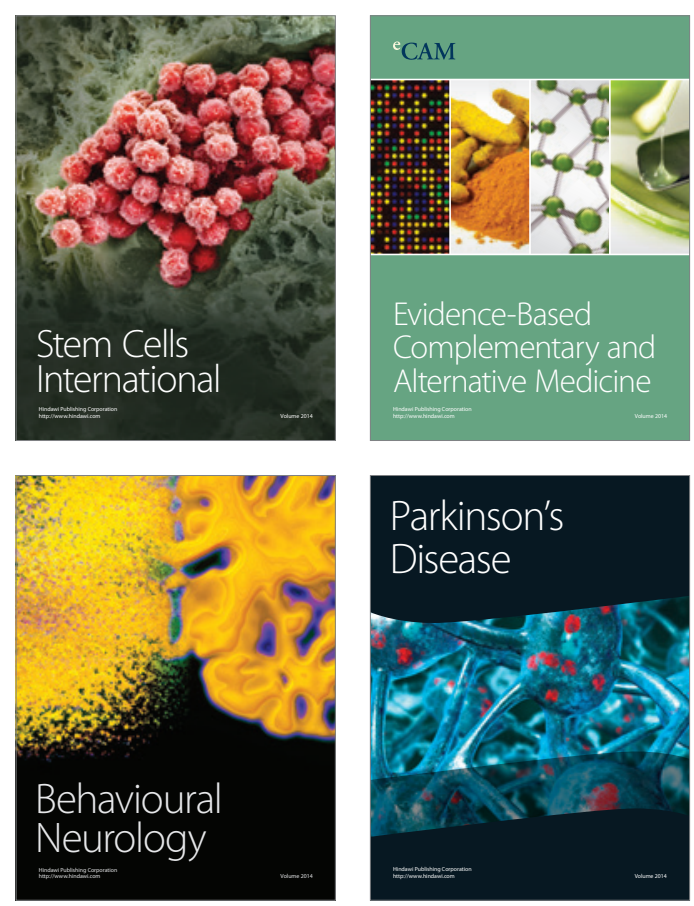

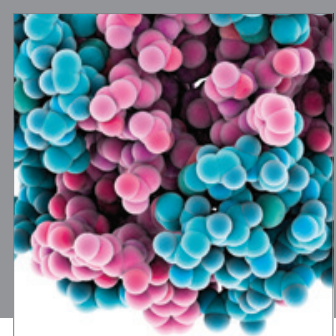

Journal of
Diabetes Research

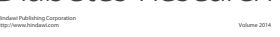

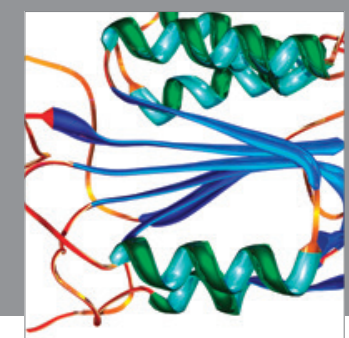

Disease Markers
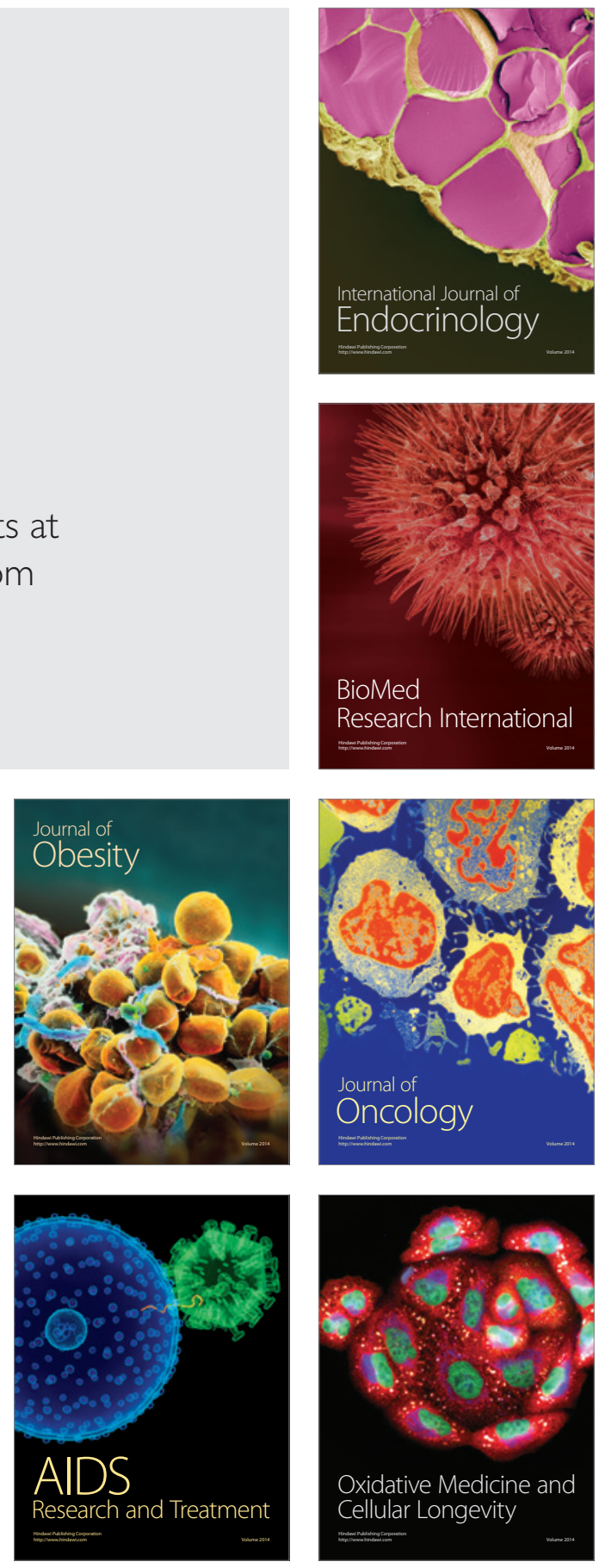